Special issue in honor of Prof. H.K. Lichtenthaler

\title{
A comparison of chlorophyll fluorescence transient measurements, using Handy PEA and FluorPen fluorometers
}

\author{
B. PADHI ${ }^{*}$, G. CHAUHAN*, D. KANDOI*, A. STIRBET ${ }^{* *}$, B.C. TRIPATHY ${ }^{*, * * *+,}$ \\ and G. GOVINDJEE ${ }^{\#,+}$ \\ School of Life Sciences, Jawaharlal Nehru University, New Mehrauli Road, 110067 New Delhi, India* \\ Anne Burras Lane, Newport News, VA 23606, USA ${ }^{* *}$ \\ Department of Biotechnology, Sharada University, 201306 Greater Noida, UP, India ${ }^{* * *}$ \\ Department of Plant Biology, Department of Biochemistry, and Center of Biophysics \& Quantitative Biology, \\ University of Illinois at Urbana-Champaign, Urbana, IL 61801, USA
}

\begin{abstract}
We provide here a general introduction on chlorophyll $(\mathrm{Chl}) a$ fluorescence, then we present our measurements on fast $(<1 \mathrm{~s})$ induction curves (the so-called OJIP transients) on dark-adapted intact leaves of Arabidopsis thaliana, under five different light intensities [in the range of $\sim 500$ to $\sim 3,000 \mu \mathrm{mol}$ (photons) $\mathrm{m}^{-2} \mathrm{~s}^{-1}$ ] using two different instruments: Handy PEA (Hansatech Instruments, UK; excitation light, $650 \mathrm{~nm}$ ) and FluorPen (model FP-110; Photon Systems Instruments, The Czech Republic; excitation light, $470 \mathrm{~nm}$ ). We then discuss the observed differences in the OJIP curves, as well as in $F_{o}\left(F_{20 \mu s}, F_{50 \mu s}\right.$, or the extrapolated $\left.F_{t \rightarrow 0}\right), F_{P}$ (the peak), and the ratios $F_{P} / F_{o}$, and $F_{v}\left(=F_{P}-F_{o}\right) / F_{P}$ in terms of differences in excitation light intensity and absorptance (or absorbance) of the excitation light by the leaves, and other factors, as well as the data available in the literature. We suggest that such measurements be accompanied, in the future, by parallel measurements on $\mathrm{Chl} a$ fluorescence imaging, an area pioneered by Hartmut K. Lichtenthaler.
\end{abstract}

Keywords: Arabidopsis thaliana; blue and red excitation light; fluorescence imaging; OJIP transient.

\section{Introduction}

Light energy absorbed by cyanobacteria, algae, and plants has three main fates: photochemistry (the process which drives photosynthesis), heat dissipation in the antenna of the photosystems, and chlorophyll (Chl) $a$ fluorescence. Although $\mathrm{Chl} a$ fluorescence is only $2-3 \%$ of the total absorbed light (Duysens 1979, Trissl et al. 1993), its

\section{Highlights}

- OJIP Chl $a$ transient from Arabidopsis was measured with two commercial fluorometers

- $\mathrm{F}_{\mathrm{o}}, \mathrm{F}_{\mathrm{P}}$, and $\mathrm{F}_{\mathrm{v}} / \mathrm{F}_{\mathrm{P}}$ values were obtained with blue $v$ s. red light, at five light intensities

- We suggest parallel measurements with fluorescence imaging and lifetime of fluorescence
Received 22 November 2020

Accepted 15 April 2021

Published online 10 May 2021

${ }^{+}$Corresponding authors

e-mail: baishnabtripathy@yahoo.com (B.C. Tripathy) gov@illinois.edu (G. Govindjee)

Abbreviations: Chl - chlorophyll; $\mathrm{F}_{\mathrm{m}}-$ maximum Chl $a$ fluorescence; $\mathrm{F}_{\mathrm{o}}$ - initial (minimal) Chl $a$ fluorescence; $\mathrm{F}_{\mathrm{v}}\left(=\mathrm{F}_{\mathrm{m}}-\mathrm{F}_{\mathrm{o}}\right)-\mathrm{variable}$ Chl $a$ fluorescence; I-step - Chl $a$ fluorescence at $\sim 30 \mathrm{~ms}$; J-step - Chl $a$ fluorescence at $\sim 2 \mathrm{~ms}$; OJIP curve - the 'fast' phase of the fluorescence transient [' $\mathrm{O}$ ' is for the initial fluorescence (at $\sim$ zero time), ' $\mathrm{P}$ ' is for peak, and ' $\mathrm{J}$ ' and ' $\mathrm{I}$ ' are inflection points between 'O' and 'P']; $\mathrm{PQ}$ - plastoquinone; $\mathrm{Q}_{\mathrm{A}}$ and $\mathrm{Q}_{\mathrm{B}}$ - the first and second plastoquinone electron acceptor of PSII.

Acknowledgments: We thank Zuzana Benedikty (of Photon Systems Instruments, The Czech Republic) for the generous gift of FluorPen (model FP-110) to one of us (G. Govindjee). We are grateful to Roland Valcke for his suggestions to relate our observations to those on fluorescence imaging, which led to substantial improvement of our paper. We are highly thankful to Hartmut Lichtenthaler, the one who we are honoring here, for reading our paper, and for making crucial suggestions, before its submission. We are also grateful to the two anonymous reviewers for their very helpful comments.

Conflict of interest: The authors declare that they have no conflict of interest. 
measurement provides insight into the photosystems as well as the overall process of photosynthesis (Govindjee et al. 1986, Shevela et al. 2019, Blankenship 2021). Light absorption by $\mathrm{Chl} a$ molecules leads to the formation of excited states (within femtoseconds), which then decay to ground state by losing energy through photochemistry $\left(\mathrm{k}_{\mathrm{p}}\right)$, internal conversion $\left(\mathrm{k}_{\mathrm{IC}}\right)$, and fluorescence $\left(\mathrm{k}_{\mathrm{f}}\right)$; these are picosecond (ps) to nanosecond (ns) processes; they are competitive in nature, i.e., change in the probability of one leads to changes in probabilities of the other two. Hence, by measuring Chl $a$ fluorescence yield, we can gain knowledge about photochemistry and heat dissipation (see e.g., Govindjee 2004, Jahns and Holzwarth 2012, Ruban et al. 2012, Murchie and Lawson 2013, Lazár 2015; also chapters in Demmig-Adams et al. 2014).

A popular method, to characterize photosynthetic samples, has been to use light intensity-dependent changes in Chl $a$ fluorescence emission of dark-adapted photosynthetic samples, during few minutes of illumination with continuous light (Kautsky and Hirsch 1931, Govindjee 1995), known as Chl $a$ fluorescence induction or fluorescence transient; during this time, electron transport in both PSI and PSII occur, followed by the Calvin-Benson cycle (Krause and Weis 1991, Maxwell and Johnson 2000, Baker 2008).

Chl $a$ fluorescence induction has been an indispensable tool, for a long time, in the study of various aspects of photosynthesis (see e.g., Neubauer and Schreiber 1987, Schreiber and Neubauer 1987, Lichtenthaler 1988, Lazár 1999, Schansker et al. 2005, 2014; Kalaji et al. 2014, 2017; Stirbet et al. 2020), including the structure, as well as the function of the photosynthetic systems (e.g., Kaňa et al. 2012, Lazár 2013, Stirbet et al. 2019, Schreiber and Klughammer 2021; chapters in Papageorgiou and Govindjee 2004). The initial part of the above-mentioned fluorescence transient curve, up to hundreds of milliseconds, has been labeled in the literature as the 'fast' phase of the fluorescence transient (also known as the OJIP transient), while the rest of the curve up to minutes, as the 'slow' phase of the fluorescence transient (see e.g., Papageorgiou and Govindjee 1968, Govindjee and Papageorgiou 1971, Bradbury and Baker 1981, Govindjee 1995, Papageorgiou et al. 2007, Stirbet and Govindjee 2011, 2016). Since these measurements are noninvasive, they are useful for obtaining a better understanding of the photochemical (and subsequent electron transfer) reactions of cyanobacteria, algae, as well as plants; further, this method is also used under field conditions, since the available commercial fluorometers are quite compact, and thus portable. Analysis of $\mathrm{Chl} a$ fluorescence induction in plants provides us with information on both PSI and PSII, especially on the maximum quantum yield of PSII photochemistry, as well as on the photosynthetic electron transport and different nonphotochemical quenching (NPQ) mechanisms in the system (see e.g., Genty et al. 1989, Kramer et al. 2004, Schreiber 2004, Strasser et al. 2004, Schreiber and Klughammer 2007, Stirbet and Govindjee 2011, Stirbet et al. 2018).

In fluorometers, used to measure $\mathrm{Chl} a$ fluorescence induction, different methods are utilized to saturate photochemistry (Röttgers 2007); further, the wavelength of the excitation light (Schreiber et al. 2012), as well as the detection window for fluorescence emission, are often different. We note that direct fluorometry with LED-based shutterless instruments (saturating pulse measurement) and pulse amplitude modulation (PAM) fluorometry (steady-state measurement; Schreiber 2004) are the ones that are most commonly used (see e.g., Kalaji et al. 2014). The color of the excitation light is important, as well as the detection window since the two photosystems (I and II) have distinct absorption and emission characteristics (see e.g., Evans 1986). Excitation light in the red, as well as in the blue regions of the spectrum is usually used in the measurement of fluorescence induction in plants. Since there are differences between the effects of red and blue light with the leaves (Vogelmann and Han 2000), we decided to study the fast $(<1 \mathrm{~s}) \mathrm{Chl} a$ fluorescence, from the ' $\mathrm{O}$ ' level to the ' $\mathrm{P}$ ' level (the OJIP transient), using these two lights, on leaves of Arabidopsis thaliana, a model plant. We also recorded the $\mathrm{F}_{\mathrm{v}}\left(=\mathrm{F}_{\mathrm{m}}-\mathrm{F}_{\mathrm{o}}\right) / \mathrm{F}_{\mathrm{m}}$ ratio, a proxy for the quantum yield of PSII photochemistry, which is also used as a sensitive indicator of plant photosynthetic performance (see e.g., Stirbet et al. 2018). For this work, we used two commercially available instruments: Handy PEA (Plant Efficiency Analyzer, Hansatech Instruments, UK; excitation $\lambda=650 \mathrm{~nm}$ ) and FluorPen FP-110 (Photon Systems Instruments, The Czech Republic; excitation $\lambda=470 \mathrm{~nm})$.

\section{Background and meaning of the OJIP transient}

By plotting Chl a fluorescence changes (measured on dark-adapted samples) on a logarithmic time scale up to $\sim 1$ s (see e.g., Fig. 1), one observes a distinct polyphasic induction curve, the so-called OJIP transient (Strasser and Govindjee 1992, Strasser et al. 1995). The fast Chl fluorescence rise, starting from the ' $\mathrm{O}$ ' level (the minimum fluorescence $\mathrm{F}_{\mathrm{o}}$, usually approximated by fluorescence at 20 or $50 \mu$ s of illumination), increases to a peak ' $\mathrm{P}$ ' with two intermediary steps, ' $\mathrm{J}$ ' (fluorescence at $2 \mathrm{~ms}, \mathrm{~F}_{\mathrm{J}}$ ) and 'I' (fluorescence at $30 \mathrm{~ms}, \mathrm{~F}_{\mathrm{I}}$ ). The $\mathrm{F}_{\mathrm{o}}$ is also referred to as the initial fluorescence, or 'origin'; it is due to energy loss in the antenna pigments before the excitation energy is trapped at the reaction centers, when all PSIIs are 'open' [i.e., with $\mathrm{Q}_{\mathrm{A}}$, the first plastoquinone (electron) acceptor of PSII, in the oxidized state].

The reduction of $\mathrm{Q}_{\mathrm{A}}$ to $\mathrm{Q}_{\mathrm{A}}^{-}$, as well as that of $\mathrm{Q}_{\mathrm{B}}$ to $\mathrm{Q}_{\mathrm{B}}{ }^{-}$(by $\mathrm{Q}_{\mathrm{A}}{ }^{-}$), predominate during the $\mathrm{OJ}$ phase (the photochemical phase), while at the end of the JI phase, the PQ pool is greatly ( $\geq 80 \%$ ) reduced (see e.g., Lazár 2009). Further, during the IP phase, since both the photosystems are simultaneously excited, the PQ pool, the Cyt $b_{6} f$ complex and plastocyanin $\left(\mathrm{PC}\right.$, which reduces $\mathrm{P} 700^{+}$, the oxidized primary donor of PSI), and the electron carriers beyond P700, up to ferredoxin (Fd), are all reduced during this phase. [We are aware that ferredoxin-NADP ${ }^{+}$reductase in plants remains inactive for a few seconds after the onset of illumination, until the stroma $\mathrm{pH}$ increases to a value $\sim 8$, when it is activated (Pschorn et al. 1988).] When the OJIP rise is measured using saturating light, the $P$ level has the maximum value $\left(F_{m}\right)$, as the electron transport chain becomes completely reduced. The ratio 
between the variable fluorescence $\left(\mathrm{F}_{\mathrm{v}}=\mathrm{F}_{\mathrm{m}}-\mathrm{F}_{\mathrm{o}}\right)$ and $\mathrm{F}_{\mathrm{m}}$ (i.e., $\mathrm{F}_{\mathrm{v}} / \mathrm{F}_{\mathrm{m}}$ ), which is a proxy of the maximum quantum yield of PSII photochemistry (Kitajima and Butler 1975, Genty et al. 1989), is one of the most used parameters obtained from the OJIP transients. Also, another wellknown parameter is the $\mathrm{F}_{\mathrm{v}} / \mathrm{F}_{\mathrm{o}}$ ratio, which is equivalent to $\mathrm{k}_{\mathrm{P}} / \mathrm{k}_{\mathrm{N}}$ (see e.g., Tsimilli-Michael 2020), where $\mathrm{k}_{\mathrm{P}}$ is the photochemical de-excitation rate constant, and $\mathrm{k}_{\mathrm{N}}$ is the nonphotochemical de-excitation rate constant of PSII (see Papageorgiou and Govindjee 2011). We recommend that, to obtain a complete picture, parallel measurements with Chl $a$ fluorescence imaging systems be included with measurements, described above (see e.g., Lichtenthaler et al. 1996, Buschmann and Lichtenthaler 1998).

\section{Materials and methods}

In this study, we used four-week-old wild type Arabidopsis thaliana plants, grown in agro peat/vermiculite $(3: 1)$ mixture in pots, under illumination with cool white, fluorescent light $\left[100 \mu \mathrm{mol}\left(\right.\right.$ photons) $\left.\mathrm{m}^{-2} \mathrm{~s}^{-1}\right]$, with $10-\mathrm{h}$ L/14-h D photoperiod. The temperature in the room was maintained at $21 \pm 1^{\circ} \mathrm{C}$, and the plants were watered twice a week. Essentially, almost identical bottom leaves were used during the measurements made with the two fluorometers (see below), since different leaves from the same plant are known to have differences in their fluorescence transients (see e.g., Küpper et al. 2019).

The OJIP transients were measured with both Handy PEA and FluorPen FP-110 instruments. The 'emitter' for Handy PEA, a LED array, is centered at $650 \mathrm{~nm}$ with NIR short-pass filters, whereas its detector is a photosensor with Kopp Corning RG-long-pass filter, for wavelengths longer than $700 \mathrm{~nm}$. In contrast, FluorPen FP-110 is equipped with a LED (OPTOSUPPLY OSB56L5111Y) centered at $\sim 470 \mathrm{~nm}$, and its detector is a PIN photodiode with bandpass filters in the $667-750 \mathrm{~nm}$ range. The maximum $(100 \%)$ intensity of light, from both the instruments (as given in their respective manuals) is $3,000 \mu \mathrm{mol}$ (photons) $\mathrm{m}^{-2} \mathrm{~s}^{-1}$. However, we measured the intensity of the excitation light provided by each of the two fluorometers, by using a LI-COR Quantum Radiometer (model LI-189) by placing the light sensor in the leaf holder of both the instruments (see the results in Table 1); on the average, the maximum intensity of the excitation light in FluorPen had $\sim 10 \%$ higher intensity than in the Handy PEA (where relevant, we will take this into account when comparing data by the two instruments). This instrument (as well as LI-190R) measures PAR over the 400-700 $\mathrm{nm}$ range, which provides energy, but then it is converted by its program, into the appropriate number of photons (light quanta). The sensitivity is automatically set, in the instrument, in such a way, that it takes into account the fact that blue photons (quanta) have more energy than the red quanta; thus, it correctly reads the quantum flux rates $[\mu$ mol(photons) $\mathrm{m}^{-2} \mathrm{~s}^{-1}$ ] of the blue and red light.

Before measurement, intact leaves of Arabidopsis thaliana were dark-adapted for $20 \mathrm{~min}$ using leaf clips, then Chl $a$ fluorescence transients (of 1-s duration, at room temperature) were measured with each instrument, under five different incident light intensities of 100, 80, $\sim 50, \sim 30$, and $\sim 20 \%$ [where $100 \%$ light intensity was $2,890 \pm 70$ and $3,120 \pm 87 \mu \mathrm{mol}$ (photons) $\mathrm{m}^{-2} \mathrm{~s}^{-1}$ for Handy PEA and FluorPen, respectively; see Table 1]. The OJIP transients were analyzed with the software provided by Photon Systems Instruments (for FluorPen) and by Hansatech Instruments (for Handy PEA). The fluorescence parameters used in this work included (1) the initial fluorescence $F_{o}$ which was estimated either as the fluorescence measured at $20 \mu \mathrm{s}\left(\mathrm{F}_{\mathrm{o}}=\mathrm{F}_{20 \mu \mathrm{s}}\right)$, or at $50 \mu \mathrm{s}\left(\mathrm{F}_{\mathrm{o}}=\mathrm{F}_{50 \mathrm{\mu s}}\right)$, or extrapolated to $\mathrm{t}=0\left(\mathrm{~F}_{\mathrm{o}}=\mathrm{F}_{\mathrm{t} \rightarrow 0}\right)$, calculated by fitting the first several fluorescence points (in the range of 20 to $80 \mu \mathrm{s}$ ) of the transient with a line that intersected the ordinate at $\mathrm{t}=0 ;(2)$ the fluorescence at the peak $\mathrm{P}, \mathrm{F}_{\mathrm{P}} ;(3)$ the variable fluorescence $\mathrm{F}_{\mathrm{v}}\left(=\mathrm{F}_{\mathrm{P}}-\mathrm{F}_{\mathrm{o}}\right)$; and (4) the $\mathrm{F}_{\mathrm{v}} / \mathrm{F}_{\mathrm{P}}$ ratio. (Note that for Handy PEA, Hansatech uses $\mathrm{F}_{20 \mu \mathrm{s}}$ as an approximation for $\mathrm{F}_{\mathrm{o}}$, and for FluorPen, Photon Systems uses $\mathrm{F}_{50 \mu \mathrm{s}}$ for the same.)

\section{Results}

Fig. 1 shows the OJIP transients measured with FluorPen and Handy PEA instruments under $100 \%$, and then

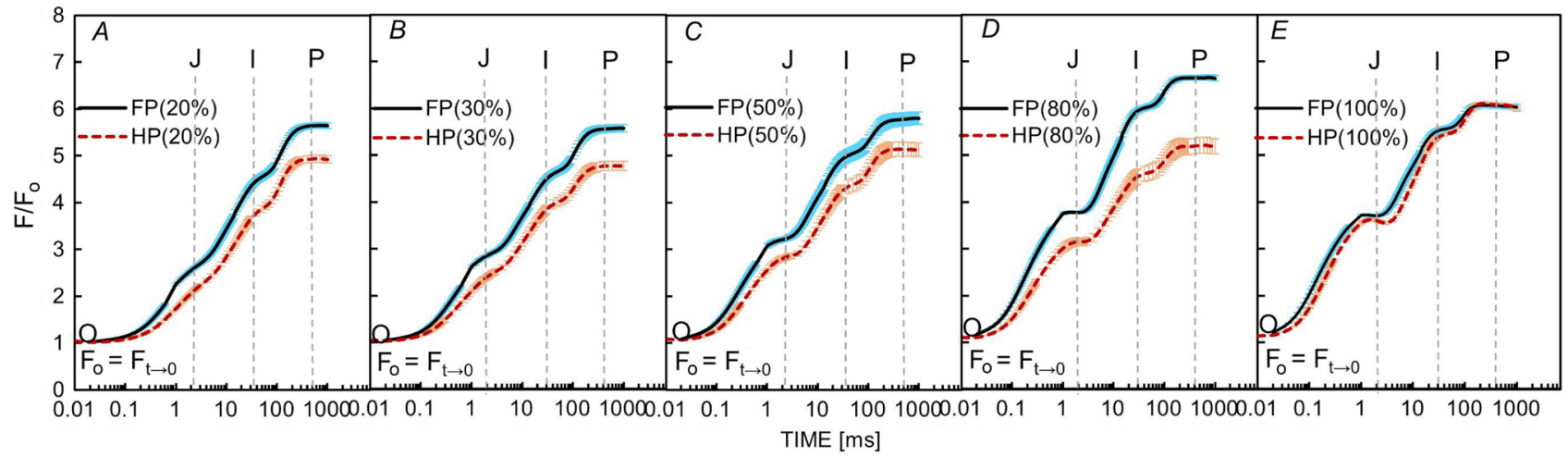

Fig. 1. The OJIP, Chl $a$ fluorescence induction, curves normalized to the extrapolated $\mathrm{F}_{\mathrm{t} \rightarrow 0}$ as $\mathrm{F}_{\mathrm{o}}$ (see 'Materials and methods'), as measured with Handy PEA (HP; excitation light, $\lambda=650 \mathrm{~nm}$ ) and FluorPen (FP; excitation light, $\lambda=470 \mathrm{~nm}$ ) on 20-min dark-adapted intact leaves of wild type Arabidopsis thaliana, under 100\% and lower light intensities [where 100\% light intensity is $2,890 \pm 70$ and $3,120 \pm 87 \mu \mathrm{mol}$ (photons) $\mathrm{m}^{-2} \mathrm{~s}^{-1}$ for HP and FP, respectively; see Table 1]. The curves, shown here, are averages of 15 replicates $\pm \mathrm{SE}$. 
approximately $80,50,30$, and $20 \%$ excitation light intensity (for details, see 'Materials and methods'); for comparison, $\mathrm{Chl}$ a induction curves were normalized to $\mathrm{F}_{\mathrm{o}}$ extrapolated at $\mathrm{t}=0\left(\mathrm{~F}_{\mathrm{t}} \rightarrow 0\right)$. We observed here clear differences between the OJIP curves obtained by the two instruments. For example, the $\mathrm{O}-\mathrm{J}$ phase (which is dependent on how much light is absorbed by the antenna pigments of PSII) rose slower and was smaller in the samples measured with Handy PEA (using red light) than those measured with FluorPen (using blue light); this is partly due to approximately $10 \%$ higher excitation light (see above), and to higher absorptance (absorption) of blue light compared to red light (see e.g., McClain and Sharkey 2020). Further, the $\mathrm{F}_{\mathrm{P}} / \mathrm{F}_{\mathrm{o}}$ ratio was higher for FluorPen than Handy PEA at almost all the light intensities used (see Fig. 1). At $100 \%$ light, $\mathrm{F}_{\mathrm{P}} / \mathrm{F}_{\mathrm{o}}$ was essentially the same with both the instruments (Fig. $1 E$ ); the value of $\mathrm{F}_{\mathrm{P}} /$ $\mathrm{F}_{\mathrm{o}}$ with FluorPen was lower here due to a higher increase in $\mathrm{F}_{\mathrm{o}}=\mathrm{F}_{\mathrm{t}} \rightarrow 0$ (Table 2). However, at $80 \%$ light, the $\mathrm{F}_{\mathrm{P}} / \mathrm{F}_{\mathrm{o}}$ with FluorPen was the highest (Fig. $1 D$ ) as $\mathrm{F}_{\mathrm{o}}=\mathrm{F}_{\mathrm{t}} \rightarrow 0$ was

Table 1. A comparison of measured light intensities [ $\mu$ mol(photons) $\mathrm{m}^{-2} \mathrm{~s}^{-1}$ ], from Handy PEA and FluorPen fluorometers (right columns), with the published values in the manuals (left column). Instrument used: LI-COR Quantum Radiometer, model LI-189 (also see 'Materials and methods'). Data are averages of three measurements \pm SE.

\begin{tabular}{llc}
\hline Light intensities, from instrument manuals & Measured light intensities (for Handy PEA) & Measured light intensities (for FluorPen) \\
\hline $3,000(100 \%)$ & $2,890 \pm 70$ & $3,120 \pm 87$ \\
$2,400(80 \%)$ & $2,314 \pm 52$ & $2,380 \pm 57$ \\
$1,500(50 \%)$ & $1,496 \pm 37$ & $1,534 \pm 55$ \\
$900(30 \%)$ & $832 \pm 39$ & $923 \pm 38$ \\
$600(20 \%)$ & $515 \pm 36$ & $598 \pm 45$ \\
\hline
\end{tabular}

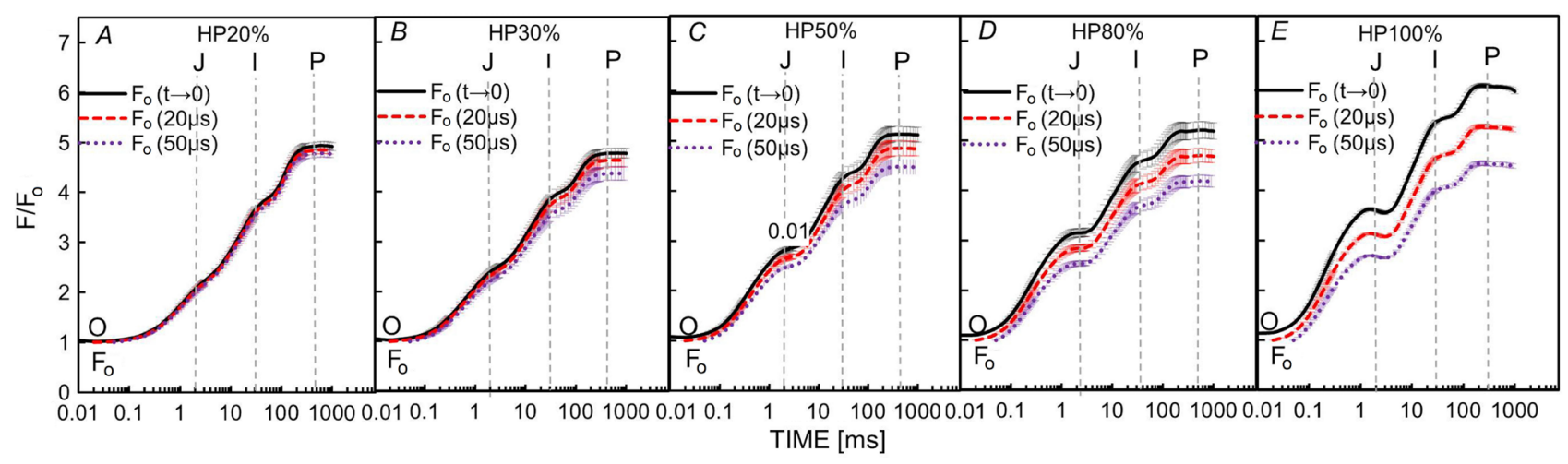

Fig. 2. Chl $a$ fluorescence induction (OJIP) curves normalized to $\mathrm{F}_{\mathrm{o}}$ extrapolated at $\mathrm{t}=0\left(\mathrm{~F}_{\mathrm{t} \rightarrow 0}\right), \mathrm{F}_{20 \mu \mathrm{s}}$, and $\mathrm{F}_{50 \mu \mathrm{s}}$, as measured with Handy PEA (excitation light, $\lambda=650 \mathrm{~nm}$ ) on 20-min dark-adapted intact leaves of wild type Arabidopsis thaliana, under different light intensities [where $100 \%$ light intensity is $2,890 \pm 70 \mu \mathrm{mol}$ (photons) $\mathrm{m}^{-2} \mathrm{~s}^{-1}$; see Table 1]. The curves are averages of 15 replicates $\pm \mathrm{SE}$.

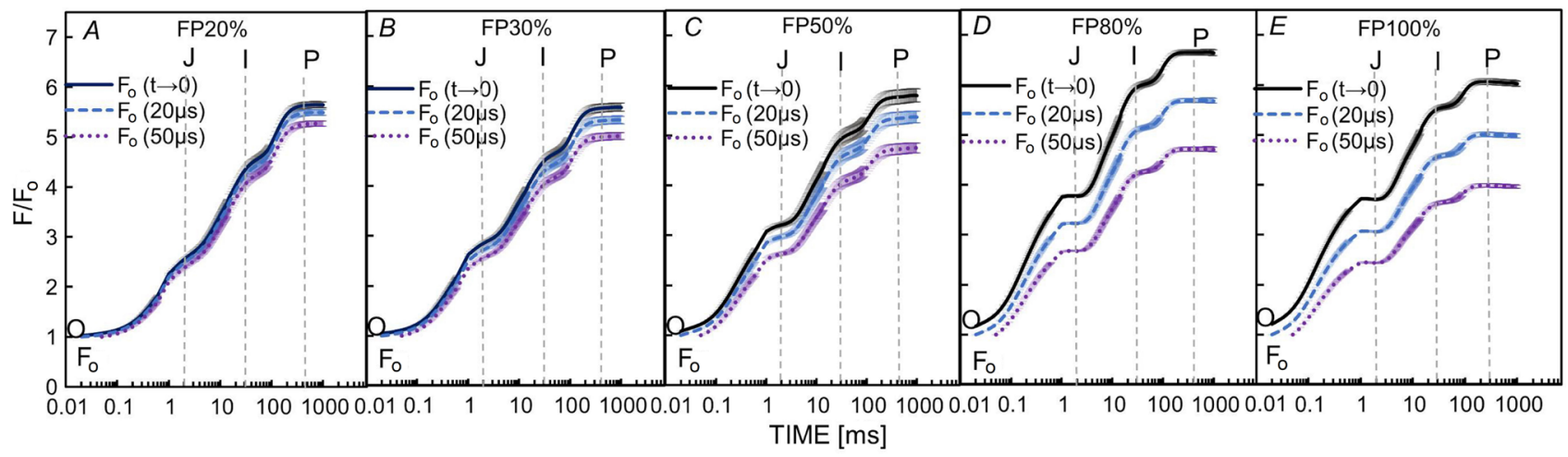

Fig. 3. Chl $a$ fluorescence induction (OJIP) curves measured under different light intensities and normalized to $\mathrm{F}_{\mathrm{o}}$ (extrapolated) at $\mathrm{t}=0\left(\mathrm{~F}_{\mathrm{t} \rightarrow 0}\right), \mathrm{F}_{20 \mu \mathrm{s}}$, and $\mathrm{F}_{50 \mu \mathrm{s}}$. Data obtained with FluorPen $(\mathrm{FP})$ (excitation light, $\lambda=470 \mathrm{~nm}$ ) on 20-min dark-adapted intact leaves of wild type Arabidopsis thaliana, under different light intensities [where $100 \%$ light intensity is $3,120 \pm 87 \mu \mathrm{mol}(\mathrm{photons}) \mathrm{m}^{-2} \mathrm{~s}^{-1}$; see Table 1 ], the curves are averages of 15 replicates \pm SE. 
lower (Table 2). This problem is, most likely, related to difficulties in getting accurate values of the extrapolated $\mathrm{F}_{\mathrm{t} \rightarrow 0}$ at high light intensities (see below).

Further, we have compared at each light intensity the OJIP transients measured with Handy PEA (Fig. 2) and FluorPen (Fig. 3), after normalization to $\mathrm{F}_{\mathrm{o}}$, to determine the effect of differently obtained $F_{o}$ values on the normalized curves. These two figures show that the curves normalized to $\mathrm{F}_{\mathrm{o}}=\mathrm{F}_{50 \mu \mathrm{s}}$ are clearly distorted as the light intensity increases, compared to those normalized to $\mathrm{F}_{\mathrm{o}}=\mathrm{F}_{20 \mu \mathrm{s}}\left(\right.$ and $\mathrm{F}_{\mathrm{t} \rightarrow 0}$ ), since a larger fraction of PSII RCs have the $\mathrm{Q}_{\mathrm{A}}$ reduced at $50 \mu \mathrm{s}$ than at $20 \mu \mathrm{s}$, while $\mathrm{Q}_{\mathrm{A}}$, in principle, must be oxidized in all PSII RCs at $\mathrm{t}=0$. Moreover, the transients measured with blue light (FluorPen) are much more affected by normalization to $\mathrm{F}_{\mathrm{o}}=\mathrm{F}_{50 \mu \mathrm{s}}\left(\right.$ and $\left.\mathrm{F}_{\mathrm{o}}=\mathrm{F}_{20 \mathrm{\mu s}}\right)$ than those measured with red light (Handy PEA), due to higher effective light intensity of the blue light, as shown in Fig. 1, which leads to an increased fraction of PSII RCs with reduced $\mathrm{Q}_{\mathrm{A}}$.

Fig. 4 shows the light intensity dependence of the peak $F_{P}$, the initial fluorescence $F_{o}\left(=F_{t \rightarrow 0}\right)$, and the $F_{v} / F_{P}$ ratio, obtained from the OJIP curves measured on intact leaves of Arabidopsis. The fluorescence intensities, measured with FluorPen, are somewhat higher than in Handy PEA, which is expected, since FluorPen and Handy PEA use different cutoff filters for the fluorescence (for details, see 'Materials and methods'). Therefore, in the following discussion, we compare the relative increase of $\mathrm{F}_{\mathrm{P}}$ and $\mathrm{F}_{\mathrm{o}}$ at five different illumination levels $[100 \%$, and $~ 80,50,30$, and $20 \%$ light, where $100 \%$ is $3,120 \pm 87$ and 2,890 $\pm 70 \mu$ mol(photons) $\mathrm{m}^{-2} \mathrm{~s}^{-1}$ for FluorPen and Handy PEA, respectively; see Table 1]. The relative increase of $\mathrm{F}_{\mathrm{P}}$, in the data obtained with both instruments, was (roughly) proportional to the increase in light intensity: i.e., as the illumination increased approximately $1.5,2.5,4$, and 5 times, the corresponding $F_{P}$ values increased essentially in the same manner (see Figs. 4 and 5). This linear dependence of $F_{P}$ with light intensity shows that all high light intensities used in this study, for both Handy PEA and FluorPen, were saturating (i.e., all $\mathrm{Q}_{\mathrm{A}}$ molecules were reduced at the P level, and thus, $F_{P}=F_{m}$; Kitajima and Butler 1975). Further, the relative increases in the three types of $F_{o}$ values are shown in Table 2; these data show that $F_{0}$, measured as $\mathrm{F}_{50 \mu \mathrm{s}}$, must be in error for higher light intensities since it increases much more than the well-known linearity predicts. However, the data for $\mathrm{F}_{20 \mu \mathrm{s}}$ is quite linear and, thus, more reliable, while, surprisingly, $\mathrm{F}_{\mathrm{t} \rightarrow 0}$ decreased at higher light intensities (Table 2). This is, perhaps, because
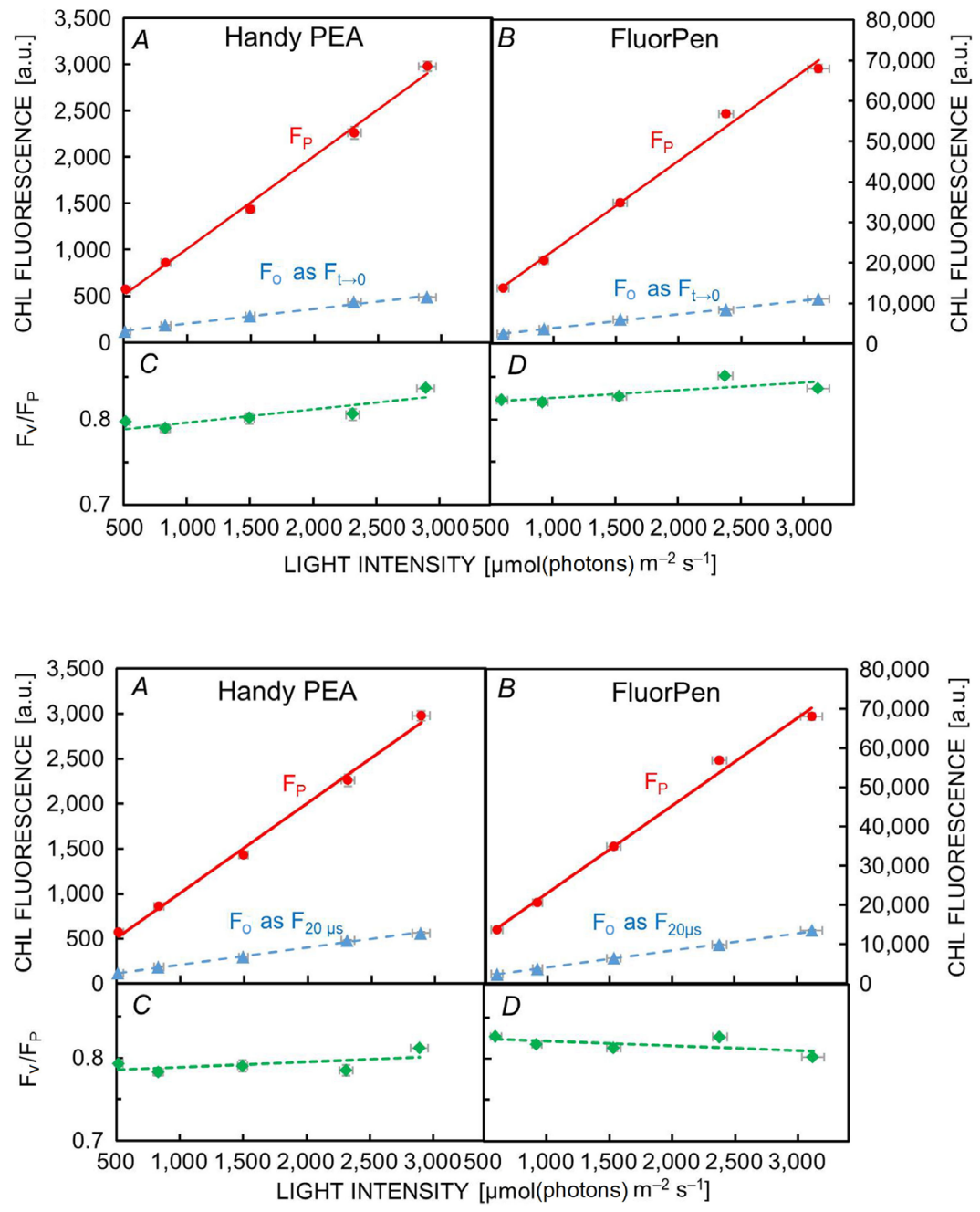

Fig. 4. The 'initial' $(\mathrm{Chl} a)$ fluorescence $\left(\mathrm{F}_{\mathrm{o}}\right.$ as extrapolated to time zero, $\left.F_{t \rightarrow 0}\right)$, the peak $\left(F_{P}\right)$, as well as the $F_{v} / F_{P}$ ratios, calculated from the OJIP curves, as measured with Fluor Pen and Handy PEA on intact leaves of wild type Arabidopsis thaliana at different excitation light intensities [where $100 \%$ is $2,890 \pm 70$ and $3,120 \pm 87 \mu \mathrm{mol}($ photons) $\mathrm{m}^{-2} \mathrm{~s}^{-1}$ for HP and FP, respectively; see Table 1]. The fluorescence data were fitted with linear trendlines. $(A) \mathrm{F}_{\mathrm{o}}$ and $\mathrm{F}_{\mathrm{P}}$ data from Handy PEA (excitation $\lambda=650 \mathrm{~nm}$ ). $(B) \mathrm{F}_{\mathrm{o}}$ and $\mathrm{F}_{\mathrm{P}}$ data from FluorPen (excitation $\lambda=470 \mathrm{~nm}) .(C, D) \mathrm{F}_{\mathrm{v}} / \mathrm{F}_{\mathrm{P}}$ ratios measured with Handy PEA and FluorPen, respectively. The data points are averages of 15 replicates $\pm \mathrm{SE}$.

Fig. 5. The initial $(\mathrm{Chl} a)$ fluorescence $\left(\mathrm{F}_{\mathrm{o}}=\right.$ $\left.F_{20 u s}\right)$, the peak $\left(F_{P}\right)$, as well as the $F_{v} / F_{P}$ ratios calculated from the OJIP curves measured, with FluorPen and Handy PEA, on intact leaves of wild type Arabidopsis thaliana at different excitation light intensities [where $100 \%$ light intensity is $2,890 \pm 70$ and $3,120 \pm 87 \mu \mathrm{mol}$ (photons) $\mathrm{m}^{-2} \mathrm{~s}^{-1}$ for HP and FP, respectively; see Table 1]. The fluorescence data were fitted with linear trendlines. $(A) \mathrm{F}_{\mathrm{o}}$ and $\mathrm{F}_{\mathrm{P}}$ data from Handy PEA (excitation $\lambda=650 \mathrm{~nm})$. $(B) \mathrm{F}_{\mathrm{o}}$ and $\mathrm{F}_{\mathrm{P}}$ data from FluorPen (excitation $\lambda=470 \mathrm{~nm}$ ). $(C, D) \mathrm{F}_{\mathrm{v}} / \mathrm{F}_{\mathrm{p}}$ ratios measured with Handy $P E A$ and FluorPen, respectively. The data points are averages of 15 replicates $\pm \mathrm{SE}$. 
Table 2. The relative increases $( \pm \mathrm{SE})$ of three different $\mathrm{F}_{\mathrm{o}}$ values with increasing light intensity: $\mathrm{F}$ extrapolated to $\mathrm{t}=0 ; \mathrm{F}$ at $\mathrm{t}=20 \mu \mathrm{s}$; and $\mathrm{F}$ at $\mathrm{t}=50 \mu \mathrm{s}$. Chlorophyll $a$ fluorescence OJIP transients were measured with FluorPen (FP) and Handy PEA (HP) fluorometers, using 20-min dark-adapted intact bottom leaves of 4-week-old wild type Arabidopsis thaliana, at five different light intensities (see Table 1), with the approximate relative light increases, noted in the left column, where 1 is for the lowest light intensity used. Data are averages of 15 replicates \pm SE.

\begin{tabular}{lllll}
\hline $\begin{array}{l}\text { Relative light increases } \\
\text { (based on data in the FP and HP manuals) }\end{array}$ & \multicolumn{3}{l}{ Relative increases of $\mathrm{F}_{\mathrm{o}}$ with increasing light intensity } \\
\hline 1.5 & FP extrapolated to $\mathrm{t}=0$ & $\mathrm{~F}$ at $\mathrm{t}=20 \mu \mathrm{s}$ & $\mathrm{F}$ at $\mathrm{t}=50 \mu \mathrm{s}$ \\
\hline & HP & $1.52 \pm 0.01$ & $1.55 \pm 0.01$ & $1.58 \pm 0.01$ \\
2.5 & $1.56 \pm 0.02$ & $1.58 \pm 0.02$ & $1.64 \pm 0.02$ \\
& FP & $2.47 \pm 0.02$ & $2.60 \pm 0.02$ & $2.82 \pm 0.02$ \\
4.0 & HP & $2.43 \pm 0.03$ & $2.52 \pm 0.03$ & $2.64 \pm 0.04$ \\
& FP & $3.48 \pm 0.03$ & $3.96 \pm 0.03$ & $4.58 \pm 0.04$ \\
5.0 & HP & $3.75 \pm 0.05$ & $4.08 \pm 0.05$ & $4.50 \pm 0.06$ \\
& FP & $4.58 \pm 0.04$ & $5.40 \pm 0.04$ & $6.50 \pm 0.05$ \\
& HP & $4.20 \pm 0.05$ & $4.78 \pm 0.06$ & $5.37 \pm 0.13$ \\
\hline
\end{tabular}

in our extrapolation to $\mathrm{t}=0$, we have not considered possible sigmoidicity of the $\mathrm{O}-\mathrm{J}$ phase, related to PSII excitonic connectivity (Joliot and Joliot 2003, Joly and Carpentier 2009, Stirbet 2013) but, instead, used a linear fitting. In our study, our focus was (and is) on comparative measurements with the FluorPen (blue excitation), Handy $P E A$ (red excitation). The overall problem of true (and real) ' $F_{o}$ ' requires further research, especially because it is crucial to obtain correct values of $\mathrm{F}_{\mathrm{v}} / \mathrm{F}_{\mathrm{m}}\left(\right.$ or $\left.\mathrm{F}_{\mathrm{v}} / \mathrm{F}_{\mathrm{P}}\right)$, and, thus, of the quantum yield of photosynthesis.

Further, the $\mathrm{F}_{\mathrm{v}} / \mathrm{F}_{\mathrm{P}}$ ratios, obtained by using $\mathrm{F}_{\mathrm{o}}=\mathrm{F}_{\mathrm{t} \rightarrow 0}$, increased with the intensity of light for Handy PEA (Fig. 4C), with values of $0.797 \pm 0.003$ (for $\sim 20 \%$ light) and $0.836 \pm 0.001$ (for $100 \%$ light); for FluorPen, they also increased (see Fig. $4 D$ ) from $0.823 \pm 0.0018(\sim 20 \%$ light) to $0.837 \pm 0.0016$ (100\% light). On the other hand, the $\mathrm{F}_{\mathrm{v}} / \mathrm{F}_{\mathrm{P}}$ ratios for Handy PEA, calculated with $\mathrm{F}_{\mathrm{o}}=\mathrm{F}_{20 \mu \mathrm{s}}$, also increased with the intensity of light (from $0.793 \pm$ 0.003 for $\sim 20 \%$ light, to $0.812 \pm 0.0016$ for $100 \%$ light; see Fig. 5C), while they slightly decreased for FluorPen (from $0.827 \pm 0.0018$ to $0.802 \pm 0.0018$; see Fig. $5 D$ ).

If we accept 0.83 as the highest $\mathrm{F}_{\mathrm{v}} / \mathrm{F}_{\mathrm{P}}$ ratio, when using $\mathrm{F}_{\mathrm{o}}=\mathrm{F}_{\mathrm{t} \rightarrow 0}$, for both FluorPen and Handy PEA, the 'true' $\mathrm{F}_{\mathrm{v}} / \mathrm{F}_{\mathrm{P}}$ value corrected for the PSI fluorescence (using 30\% as contribution of PSI to $\mathrm{F}_{\mathrm{o}}$; see Pfündel 1998, Rappaport et al. 2007) would be 0.88 (see Table 2 in Stirbet and Govindjee 2012), which is close to 0.91 (both $~ 0.9$ ), obtained by Wientjes et al. (2013) for plants acclimated to high light. Note that due to different detection windows of the two instruments, used here (see 'Materials and methods'), the contribution of PSI fluorescence to $\mathrm{F}_{\mathrm{o}}$ is lower in FluorPen than in Handy PEA, and thus, the uncorrected $\mathrm{F}_{\mathrm{v}} / \mathrm{F}_{\mathrm{m}}$ ratios determined with FluorPen at different light intensities (see Figs. 4 and 5) were slightly higher than those determined with Handy PEA.

\section{Discussion}

All the experimental results, taken together, show that the OJIP transients measured under five different light intensities (see Table 1) on intact leaves of Arabidopsis thaliana plants grown under controlled (normal) conditions (Fig. 1), as well as the values of $F_{\mathrm{o}}, \mathrm{F}_{\mathrm{P}}, \mathrm{F}_{\mathrm{v}} / \mathrm{F}_{\mathrm{P}}$, and $\mathrm{F}_{\mathrm{v}} / \mathrm{F}_{\mathrm{o}}$ obtained from these data (Fig. 4), are somewhat different when a Handy $P E A$ (using red excitation) or a FluorPen (using blue excitation, and slightly higher light intensity) was used. Our results on OJIP Chl $a$ fluorescence transients, with two different highly-used instruments, presented in this paper (Figs. 1-4), emphasize two major points: (1) Choice of $\mathrm{F}_{\mathrm{o}}$ is crucial $-\mathrm{F}_{\mathrm{o}}$ at $20 \mu \mathrm{s}$ is much more reliable than that at $50 \mu$ s because, in all likelihood, there is higher concentration of reduced $\mathrm{Q}_{\mathrm{A}}$ at the longer time; although the use of $F_{o}$ extrapolated linearly from $80 \mu \mathrm{s}$ to zero time, as we did here, is, in principle, better, further experiments are needed on this issue. (2) The wavelength of excitation is important; because of slightly higher excitation light and absorptance (absorption), by leaves, of $470 \mathrm{~nm}$ (blue) light, used in FluorPen, than of $650 \mathrm{~nm}$ (red) light ( $c f$. McClain and Sharkey 2020), the 'artefact' for ' $F_{o}$ ' is higher in the former. This seems obvious from the higher initial slope of the $\mathrm{O}-\mathrm{J}$ phase measured with FluorPen than with Handy PEA, for almost all the light intensities used. The $\mathrm{F}_{\mathrm{v}} / \mathrm{F}_{\mathrm{P}}$ ratios, calculated by using $\mathrm{F}_{\mathrm{o}}=\mathrm{F}_{\mathrm{t} \rightarrow 0}$, increased with light intensity for both FluorPen and Handy PEA, but with a higher slope for Handy PEA (Fig. $4 C, D)$; their highest values being the same $(0.836-$ 0.837 ), characteristic of many normal (non-stressed) plants. However, as mentioned earlier, and is well known, Chl fluorescence from PSI influences the $F_{v} / F_{P}$ ratio, and, thus, a correction must be made to determine the correct $\mathrm{F}_{\mathrm{v}} / \mathrm{F}_{\mathrm{P}}$, to obtain the true quantum yield of PSII (see e.g., Pfündel 1998, 2021; Wientjes et al. 2013, Pfündel et al. 2018).

We note that different colors of excitation light influence various reactions in photosynthetic samples. For example, the action spectra of PSII photoinhibition, measured on isolated thylakoids (Hakala et al. 2005), as well as on Arabidopsis leaves (Sarvikas et al. 2006), show a relatively similar photoinhibition at $470 \mathrm{~nm}$ and $650 \mathrm{~nm}$. However, the relative PSII and PSI contributions to the total fluorescence vary with excitation wavelength, as they have different pigment composition, partly due to the presence 
of different chlorophyll-carotenoid protein complexes (see e.g., Lichtenthaler et al. 1982a,b; Boichenko et al. 1998, Santabarbara et al. 2019). Moreover, since PSI has practically no variable fluorescence (Pfündel 1998, Franck et al. 2002; see, however, Lazár 2013, Schreiber and Klughammer 2021), its contribution to $\mathrm{F}_{\mathrm{o}}$ is higher $(\sim 30-50 \%)$ than that to $\mathrm{F}_{\mathrm{P}}(<10 \%)$ (Pfündel 1998, 2021; Pfündel et al. 2013). Thus, the $\mathrm{F}_{\mathrm{v}} / \mathrm{F}_{\mathrm{m}}$ ratio also varies with the excitation wavelength (Pfündel 2009), being positively correlated with the PSII/PSI absorption ratio, a maximum in the action spectrum of $F_{v} / F_{m}$ indicating a higher light absorption by PSII relative to PSI.

On the other hand, measurements of Chl fluorescence profiles and gradients of absorbed light of different colors in spinach leaves have shown that blue light is absorbed in the first $150-\mu \mathrm{m}$ layer beneath the irradiated surface, followed by red light $(200 \mu \mathrm{m})$, and then green light $(300 \mu \mathrm{m})$ (Vogelmann and Han 2000, Evans 2009, Sharkey 2020). This suggests that the blue light, used in FluorPen (FP-110), may not only have a higher excitation light and leaf absorptance (absorption) than the red light used by Handy PEA, but it also samples a different population of chloroplasts in the leaf than the red light. Chloroplasts closer to the surface see more light, and behave more like sun-acclimated chloroplasts, with increased $\mathrm{Chl} a / b$ ratio, and greater cytochrome $b_{6} / f$ and Rubisco content per Chl than the chloroplasts located deeper in the leaf (Terashima and Inoue 1985). The fact is that blue light is absorbed in the light-harvesting Chl protein complexes (LHCPs) in the thylakoid membranes by both the yellow carotenoids and by the two chlorophylls. In contrast, red light is only absorbed by the two chlorophylls and therefore penetrates deeper into the leaf, i.e., also in deeper chloroplast layers not reached by blue excitation light.

Furthermore, due to the overlap with the in vivo absorption band of the Chl-protein complexes, the reabsorption of some of the emitted Chl $a$ fluorescence decreases the $\mathrm{F}_{690}$ (red) band to a much higher degree than the $\mathrm{F}_{730}$ (far-red) band (Gitelson et al. 1998, for chloroplasts, see Govindjee and Yang 1966). Thus, the emission spectra induced by red light, which penetrates deeper into the leaf, has a fluorescence peak mainly in the far-red, near $735 \mathrm{~nm}$, since a large portion of the $\mathrm{F}_{690}$ is reabsorbed on its way from deeper leaf layers to the leaf surface (see e.g., Rinderle and Lichtenthaler 1988). However, Chl fluorescence emission spectra, obtained by excitation with blue light, have a distinctly higher peak at $690 \mathrm{~nm}$, and a lower peak or shoulder at $735 \mathrm{~nm}$. These observations then indicate that blue light, although it may be somewhat less effective in photosynthetic quantum conversion, as compared to red light, gives a higher intensity of $\mathrm{Chl}$ fluorescence, because the latter is less reabsorbed since it predominantly comes from the upper chloroplasts closer to the leaf surface. This fact seems to be a major cause for the differences in the blue and red light induced OJIP transients of leaves, as presented here.

\section{Concluding remarks}

In conclusion, our measurements of the OJIP transients on the leaves of Arabidopsis thaliana plants with FluorPen (using blue excitation light; $\lambda=470 \mathrm{~nm}$ ), compared to those with Handy PEA (using red excitation light; $\lambda=650 \mathrm{~nm}$ ), indicate that blue light has a higher leaf absorptance (absorption) than the red light (Fig. 1), which is supported by, e.g., data of McClain and Sharkey (2020). In principle, the increased intensity of the blue light should have no effect on the $F_{v} / F_{m}$ ratio. However, the three different values of ' $\mathrm{F}_{\mathrm{o}}$ ' (i.e., $\mathrm{F}_{\mathrm{t} \rightarrow 0}, \mathrm{~F}_{20 \mu \mathrm{s}}$, and $\mathrm{F}_{50 \mu \mathrm{s}}$ ) affect differently the normalization of the OJIP curves (Figs. 2, 3), and the values of the quantum yield of PSII photochemistry (inferred from the $\mathrm{F}_{\mathrm{v}} / \mathrm{F}_{\mathrm{m}}$ ratio) (Figs. $4 C, D ; 5 C, D$ ). These 'errors' were, as expected, higher for $\mathrm{F}_{50 \mathrm{\mu s}}$ than $\mathrm{F}_{20 \mathrm{\mu s}}$ and $\mathrm{F}_{\mathrm{t} \rightarrow 0}$, as well as higher for blue light (FluorPen) than red light (Handy PEA) due to its increased excitation light intensity and of the leaf absorptance (absorption), which induce a higher fraction of PSII RCs with $\mathrm{Q}_{\mathrm{A}}$ reduced at higher light intensities. Thus, it is important to be aware of these differences in $\mathrm{Chl} a$ fluorescence induction measurements with the two instruments, used here, which use different excitation light. However, it is acceptable to use the same instrument for comparing photosynthetic activities between different samples.

Measurements of $\mathrm{Chl} a$ fluorescence transients, used here, provide information on single leaf spots. A more powerful and advanced technique is the imaging of Chl $a$ fluorescence of a larger leaf area or whole leaves providing the individual fluorescence information on several hundred or thousand leaf pixels. We note that Küpper et al. (2019) have shown that the direct method of Chl $a$ fluorescence transient measurement, used here, and in the literature, are supported by their data on direct fast imaging with a new version of the macroscopic FluorCam instrument (Photon Systems Instruments), which uses for excitation the same type of blue LEDs and similar cutoff filters for the fluorescence detection as FluorPen FP-110, used here. However, compared to nonimaging measurements, the fluorescence imaging systems enable a much more accurate estimation of the extent and development of stress, since they also allow evaluation of the heterogeneity of measured parameters and the detection of smaller or larger gradients over the leaf area.

Chl $a$ fluorescence imaging systems have been used since the mid 1990s (see e.g., Lang et al. 1994, Edner et al. 1995, Genty and Meyer 1995, Lichtenthaler and Miehé 1997, Lichtenthaler and Babani 2000, Lichtenthaler et al. 2005, Küpper et al. 2007, Pérez-Bueno et al. 2019). Blue light excitation systems have been used in studies with several imaging systems (see e.g., Lichtenthaler et al. 2000, Nedbal et al. 2000, Barbagallo et al. 2003, Chen et al. 2009). Further, an orange/white LED excitation system was used by Cen et al. (2017). Multicolor fluorescence imaging systems, including the measurement of the blue and green fluorescence of leaves, as well as the red and far-red Chl $a$ fluorescence, using UV-A radiation (340 to $398 \mathrm{~nm}$ ) as excitation source were used, e.g., by Lang et al. (1994), Lichtenthaler et al. (1996), Buschmann and Lichtenthaler (1998), Sowinska et al. (1999), and PérezBueno et al. (2016). Some of these instruments also allow the user to apply special blue or red filters (with white light as excitation source) to obtain a higher Chl fluorescence yield, using blue or red excitation as compared to UV-A 
excitation. On the other hand, Langsdorf et al. (2000), Heisel et al. (1997), and Sun et al. (2020) have shown that $\mathrm{Chl} a$ fluorescence studies including fluorescence imaging can be used in 'nitrogen management', since they observed a clear relation between $\mathrm{Chl} a$ fluorescence images and nitrogen status of the plants. In addition to fluorescence intensity measurements, we recommend the use of lifetime of fluorescence imaging as well since it allows one to measure the true quantum yield of PSII (see Holub et al. 2000, 2007; Wientjes et al. 2013).

In conclusion, the differences in the fast Chl fluorescence induction on Arabidopsis thaliana plants, obtained with FluorPen FP-110 (blue excitation $\sim 470 \mathrm{~nm}$ ) with those with Handy PEA (red excitation, $650 \mathrm{~nm}$ ), are mainly due to increased effectiveness of the blue light in Chl fluorescence coming from the outer upper layers of the leaf and to the deeper penetration of the red light also into lower leaf and chloroplast layers, and to about $10 \%$ higher light intensity in FluorPen (see Table 1). However, the $F_{v} / F_{m}$ ratios measured with these instruments were comparable, when using $\mathrm{F}_{20 \mu \mathrm{s}}$ and $\mathrm{F}_{\mathrm{t} \rightarrow 0}$. We emphasize that some of the issues discussed in this report are also important for a proper interpretation of the $\mathrm{Chl} a$ fluorescence results obtained in imaging experiments, and vice versa.

\section{References}

Baker N.R.: Chlorophyll fluorescence: a probe of photosynthesis in vivo. - Annu. Rev. Plant Biol. 59: 89-113, 2008.

Barbagallo R.P., Oxborough K., Pallett K.E., Baker N.R.: Rapid, noninvasive screening for perturbations of metabolism and plant growth using Chlorophyll Fluorescence Imaging. Plant Physiol. 132: 485-493, 2003.

Blankenship R.E.: Molecular Mechanisms of Photosynthesis. $3^{\text {rd }}$ Edition. Pp. 320. Wiley-Blackwell, Oxford 2021.

Boichenko V.A.: Action spectra and functional antenna sizes of Photosystems I and II in relation to the thylakoid membrane organization and pigment composition. - Photosynth. Res. 58: 163-174, 1998 .

Bradbury M., Baker N.R.: Analysis of the slow phases of the in vivo chlorophyll fluorescence induction curve. Changes in the redox state of photosystem II electron acceptors and fluorescence emission from photosystem I and II. BBA-Bioenergetics 635: 542-551, 1981.

Buschmann C., Lichtenthaler H.K.: Principles and characteristics of multi-colour fluorescence imaging of plants. - J. Plant Physiol. 152: 297-314, 1998

Cen H., Weng H., Yao J. et al.: Chlorophyll fluorescence imaging uncovers photosynthetic fingerprint of citrus Huanglongbing.Front. Plant Sci. 8: 1509, 2017.

Chen C.P., Frank T.D., Long S.P.: Is a short, sharp shock equivalent to long-term punishment? Contrasting the spatial pattern of acute and chronic ozone damage to soybean leaves via chlorophyll fluorescence imaging. - Plant Cell Environ. 32: 327-335, 2009

Demmig-Adams B., Garab G., Adams III W.W., Govindjee G. (ed.): Non-photochemical Quenching and Energy Dissipation in Plants, Algae and Cyanobacteria. Advances in Photosynthesis and Respiration. Vol. 40. Pp. 649. Springer, Dordrecht 2014.

Duysens L.N.M.: Transfer and trapping of excitation energy in photosystem II. - In: Wolstenholme G.E.W., Fitzsimons D.W. (ed.): Chlorophyll Organization and Energy Transfer in Photosynthesis. Ciba Foundation Symposium 61 (New Series). Pp. 323-340. Excerpta Medica, Amsterdam-New York, 1979.

Edner H., Johansson J., Svanberg S. et al.: Remote multi-colour fluorescence imaging of selected broad-leaf plants. - EARSel Adv. Remote Sens. 3: 2-14, 1995.

Evans J.R.: A quantitative analysis of light distribution between the two photosystems, considering variation in both the relative amounts of the chlorophyll-protein complexes and the spectral quality of light. - Photobiochem. Photobiophys. 10: 135-147, 1986.

Evans J.R.: Potential errors in electron transport rates calculated from chlorophyll fluorescence as revealed by a multilayer leaf model. - Plant Cell Physiol. 50: 698-706, 2009.

Franck F., Juneau P., Popovic R.: Resolution of the photosystem I and photosystem II contributions to chlorophyll fluorescence of intact leaves at room temperature. - BBA-Bioenergetics 1556: 239-246, 2002

Genty B., Briantais J.-M., Baker N.R.: The relationship between the quantum yield of photosynthetic electron transport and quenching of chlorophyll fluorescence. - BBA-Gen. Subjects 990: 87-92, 1989.

Genty B., Meyer S.: Quantitative mapping of leaf photosynthesis using chlorophyll fluorescence imaging. - Aust. J. Plant Physiol. 22: 277-284, 1995.

Gitelson A.A., Buschmann C., Lichtenthaler H.K.: Leaf chlorophyll fluorescence corrected for re-absorption by means of absorption and reflectance measurements. - J. Plant Physiol. 152: 283-296, 1998.

Govindjee G.: Sixty-three years since Kautsky: Chlorophyll $a$ fluorescence. - Aust. J. Plant Physiol. 22: 131-160, 1995.

Govindjee G.: Chlorophyll $a$ fluorescence: a bit of basics and history. - In: Papageorgiou G.C, Govindjee G. (ed.): Chlorophyll $a$ Fluorescence: A Signature of Photosynthesis. Advances in Photosynthesis and Respiration. Vol. 19. Pp. 1-41, Springer, Dordrecht 2004.

Govindjee G., Amesz J., Fork D.C. (ed.): Light Emission by Plants and Bacteria. Pp. 660. Academic Press, Orlando 1986.

Govindjee G., Papageorgiou G.C.: Chlorophyll fluorescence and photosynthesis: fluorescence transients. - In: Giese A.C. (ed.): Photophysiology: Current Topics in Photobiology and Photochemistry. Vol. 6. Pp. 1-46, Academic Press, New York 1971.

Govindjee G., Yang L.: Structure of the red fluorescence band in chloroplasts. - J. Gen. Physiol. 49: 763-780, 1966.

Hakala M., Tuominen I., Keränen M. et al.: Evidence for the role of the oxygen-evolving manganese complex in photoinhibition of Photosystem II. - BBA-Bioenergetics 1706: 68-80, 2005.

Heisel F., Sowinska M., Khalili E. et al:: Laser-induced fluorescence imaging for monitoring nitrogen fertilizing treatments of wheat. - Proc. SPIE 3059: 10-21, 1997.

Holub O., Seufferheld M.J., Gohlke C. et al.: Fluorescence lifetime imaging (LFI) in real-time - a new technique in photosynthesis research. - Photosynthetica 38: 581-599, 2000.

Holub O., Seufferheld M.J., Gohlke C. et al.: Fluorescence lifetime imaging microscopy of Chlamydomonas reinhardtii: non-photochemical quenching mutants and the effect of photosynthetic inhibitors on the slow fluorescence transient. J. Microsc. 226: 90-120, 2007.

Jahns P., Holzwarth A.R.: The role of the xanthophyll cycle and of lutein in photoprotection of photosystem II. BBA-Bioenergetics 1817: 182-193, 2012.

Joliot P., Joliot A.: Excitation transfer between photosynthetic units: the 1964 experiment. - Photosynth. Res. 76: 241-245, 2003. 
Joly D., Carpentier R.: Sigmoidal reduction kinetics of the photosystem II acceptor side in intact photosynthetic materials during fluorescence induction. - Photoch. Photobio. Sci. 8: 167-173, 2009.

Kalaji H.M., Schansker G., Brestic M. et al.: Frequently asked questions about chlorophyll fluorescence, the sequel. Photosynth. Res. 132: 13-66, 2017.

Kalaji H.M., Schansker G., Ladle R.J. et al.: Frequently asked questions about chlorophyll fluorescence: practical issues. Photosynth. Res. 122: 121-158, 2014.

Kautsky H., Hirsch A.: Neue Versuche zur Kohlensäureassimilation. - Naturwissenschaften 19: 964, 1931.

Kaňa R., Kotabová E., Komárek O. et al.: The slow $\mathrm{S}$ to $\mathrm{M}$ fluorescence rise in cyanobacteria is due to a State 2 to State 1 transition. - BBA-Bioenergetics 1817: 1237-1247, 2012.

Kitajima M., Butler W.L.: Quenching of chlorophyll fluorescence and primary photochemistry in chloroplasts by dibromothymoquinone. - BBA-Bioenergetics 376: 105-115, 1975.

Kramer D.M., Johnson G., Kiirats O., Edwards G.E.: New fluorescence parameters for the determination of $\mathrm{Q}_{\mathrm{A}}$ redox state and excitation energy fluxes. - Photosynth. Res. 79: 209$218,2004$.

Krause G.H., Weis E.: Chlorophyll fluorescence and photosynthesis: The basics. - Annu. Rev. Plant Phys. 42: 313-349, 1991.

Küpper H., Benedikty Z., Morina F. et al.: Analysis of OJIP chlorophyll fluorescence kinetics and $\mathrm{Q}_{\mathrm{A}}$ reoxidation kinetics by direct fast imaging. - Plant Physiol. 179: 369-381, 2019.

Küpper H., Parameswaran A., Leitenmaier B. et al.: Cadmiuminduced inhibition of photosynthesis and long-term acclimation to cadmium stress in the hyperaccumulator Thlaspi caerulescens. - New Phytol. 175: 655-674, 2007.

Lang M., Lichtenthaler H.K., Sowinska M. et al.: Blue, green and red fluorescence signatures and images of tobacco leaves. - Plant Biol. 107: 230-236, 1994.

Langsdorf G., Buschmann C., Babani F. et al.: Multicolour fluorescence imaging of sugar beet leaves with different $\mathrm{N}$-status by flash lamp UV-excitation. - Photosynthetica 38: 539-551, 2000.

Lazár D.: Chlorophyll a fluorescence induction. - Biochim. Biophys. Acta 1412: 1-28, 1999.

Lazár D.: Modelling of light-induced chlorophyll $a$ fluorescence rise (O-J-I-P transient) and changes in $820 \mathrm{~nm}$-transmittance signal of photosynthesis. - Photosynthetica 47: 483-498, 2009.

Lazár D.: Simulations show that a small part of variable chlorophyll a fluorescence originates in photosystem I and contributes to overall fluorescence rise. - J. Theor. Biol. 335: 249-264, 2013.

Lazár D.: Parameters of photosynthetic energy partitioning. J. Plant Physiol. 175: 131-147, 2015.

Lichtenthaler H.K.: In vivo chlorophyll fluorescence as a tool for stress detection in plants. - In: Lichtenthaler H.K. (ed.): Applications of Chlorophyll Fluorescence in Photosynthesis Research, Stress Physiology, Hydrobiology and Remote Sensing. Pp. 129-142, Kluwer Academic Publishers, Dordrecht, 1988.

Lichtenthaler H.K., Babani F.: Detection of photosynthetic activity and water stress by imaging the red chlorophyll fluorescence. - Plant Physiol. Bioch. 38: 889-895, 2000.

Lichtenthaler H.K., Babani F., Langsdorf G., Buschmann C.: Measurement of differences in red chlorophyll fluorescence and photosynthetic activity between sun and shade leaves by fluorescence imaging. - Photosynthetica 38: 521-529, 2000.

Lichtenthaler H.K., Kuhn G., Prenzel U. et al.: Adaptation of chloroplast-ultrastructure and of chlorophyll-protein levels to high-light and low-light growth conditions. - Z. Naturforsch. 37c: $464-475,1982 b$.

Lichtenthaler H.K., Lang M., Sowinska M. et al.: Detection of vegetation stress via a new high resolution fluorescence imaging system. - J. Plant Physiol. 148: 599-612, 1996.

Lichtenthaler H.K., Langsdorf G., Lenk S., Buschmann C.: Chlorophyll fluorescence imaging of photosynthetic activity with the flash-lamp fluorescence imaging system. Photosynthetica 43: 355-369, 2005.

Lichtenthaler H.K., Miehé J.A.: Fluorescence imaging as a diagnostic tool for plant stress. - Trends Plant Sci. 2: 316320, 1997.

Lichtenthaler H.K., Prenzel U., Kuhn G.: Carotenoid composition of chlorophyll-carotenoid-proteins from radish chloroplasts. Z. Naturforsch. 37c: 10-12, 1982a.

Lichtenthaler H.K., Rinderle U.: The role of chlorophyll fluorescence in the detection of stress conditions in plants. Crit. Rev. Anal. Chem. 19: S29-S85, 1988.

Maxwell K., Johnson G.N.: Chlorophyll fluorescence a practical guide. - J. Exp. Bot. 51: 659-668, 2000.

McClain A.M., Sharkey T.D.: Building a better equation for electron transport estimated from $\mathrm{Chl}$ fluorescence: accounting for non-photosynthetic light absorption. - New Phytol. 225: 604-608, 2020.

Murchie E.H., Lawson T.: Chlorophyll fluorescence analysis: a guide to good practice and understanding some new applications. - J. Exp. Bot. 64: 3983-3998, 2013.

Nedbal L., Soukupová J., Kaftan D. et al.: Kinetic imaging of chlorophyll fluorescence using modulated light. - Photosynth. Res. 66: 3-12, 2000.

Neubauer C., Schreiber U.: The polyphasic rise of chlorophyll fluorescence upon onset of strong continuous illumination: I. Saturation characteristics and partial control by the photosystem II acceptor side. - Z. Naturforsch. 42c: 12461254, 1987.

Papageorgiou G.C., Govindjee G.: Light-induced changes in the fluorescence yield of chlorophyll $a$ in vivo. I. Anacystis nidulans. - Biophys J. 8: 1299-1315, 1968.

Papageorgiou G.C., Govindjee G. (ed.): Chlorophyll a Fluorescence: A Signature of Photosynthesis. Advances in Photosynthesis and Respiration. Vol. 19. Pp. 818. Springer, Dordrecht 2004.

Papageorgiou G.C., Govindjee G.: Photosystem II fluorescence: Slow changes - scaling from the past. - J. Photoch. Photobio. B 104: 258-270, 2011.

Papageorgiou G.C., Tsimilli-Michael M., Stamatakis K.: The fast and slow kinetics of chlorophyll $a$ fluorescence induction in plants, algae and cyanobacteria: a viewpoint. - Photosynth. Res. 94: 275-290, 2007.

Pérez-Bueno M.L., Pineda M., Barón M.: Phenotyping plant responses to biotic stress by chlorophyll fluorescence imaging. - Front. Plant Sci. 10: 1135, 2019.

Pérez-Bueno M.L., Pineda M., Cabeza F.M., Barón M.: Multicolor fluorescence imaging as a candidate for disease detection in plant phenotyping. - Front. Plant Sci. 7: 1790, 2016.

Pfündel E.E.: Estimating the contribution of photosystem I to total leaf chlorophyll fluorescence. - Photosynth. Res. 56: 185-195, 1998.

Pfündel E.E.: Deriving room temperature excitation spectra for photosystem I and photosystem II fluorescence in intact leaves from the dependence of $\mathrm{F}_{\mathrm{V}} / \mathrm{F}_{\mathrm{M}}$ on excitation wavelength. Photosynth. Res. 100: 163-177, 2009.

Pfündel E.E.: Simultaneously measuring pulse-amplitudemodulated (PAM) chlorophyll fluorescence of leaves at wavelengths shorter and longer than $700 \mathrm{~nm}$. - Photosynth. Res. 147: 345-358, 2021. 
Pfündel E.E., Klughammer C., Meister A., Cerovic Z.G.: Deriving fluorometer-specific values of relative PSI fluorescence intensity from quenching of Fo fluorescence in leaves of Arabidopsis thaliana and Zea mays. - Photosynth. Res. 114: 189-206, 2013.

Pfündel E.E., Latouche G., Meister A., Cerovic Z.G.: Linking chloroplast relocation to different responses of photosynthesis to blue and red radiation in low and high light-acclimated leaves of Arabidopsis thaliana (L.). - Photosynth. Res. 137: 105-128, 2018.

Pschorn R., Rühle W., Wild A.: The influence of the proton gradient on the activation of ferredoxin-NADP ${ }^{+}$-oxidoreductase by light. - Z. Naturforsch. 43c: 207-212, 1988.

Rappaport F., Béal D., Joliot A., Joliot P.: On the advantages of using green light to study fluorescence yield changes in leaves. - BBA-Bioenergetics 1767: 56-65, 2007.

Rinderle U., Lichtenthaler H.K.: The chlorophyll fluorescence ratio $\mathrm{F}_{690} / \mathrm{F}_{735}$ as a possible stress indicator. - In: Lichtenthaler H.K. (ed.): Applications of Chlorophyll Fluorescence in Photosynthesis Research, Stress Physiology, Hydrobiology and Remote Sensing. Pp. 189-196, Kluwer Academic Publishers, Dordrecht 1988.

Röttgers R.: Comparison of different variable chlorophyll $a$ fluorescence techniques to determine photosynthetic parameters of natural phytoplankton. - Deep Sea Res. Part I Oceanogr. Res. Pap. 54: 437-451, 2007.

Ruban A.V., Johnson M.P., Duffy C.D.F.: The photoprotective molecular switch in the photosystem II antenna. - BBABioenergetics 1817: 167-181, 2012.

Santabarbara S., Villafiorita Monteleone F., Remelli W. et al.: Comparative excitation-emission dependence of the $F_{v} / F_{m}$ ratio in model green algae and cyanobacterial strains. Physiol. Plantarum 166: 351-364, 2019.

Sarvikas P., Hakala M., Pätsikkä E. et al.: Action spectrum of photoinhibition in leaves of wild type and npq1-2 and npq4-1 mutants of Arabidopsis thaliana. - Plant Cell Physiol. 47: 391-400, 2006

Schansker G., Tóth S.Z., Holzwarth A.R., Garab G.: Chlorophyll $a$ fluorescence: beyond the limits of the $\mathrm{Q}_{\mathrm{A}}$ model. Photosynth. Res. 120: 43-58, 2014.

Schansker G., Tóth S.Z., Strasser R.J.: Methylviologen and dibromorhymoquinone treatments of pea leaves reveal the role of photosystem I in the $\mathrm{Chl} a$ fluorescence rise OJIP. BBA-Bioenergetics 1706: 250-261, 2005.

Schreiber U.: Pulse-amplitude (PAM) fluorometry and saturation pulse method: An overview. - In: Papageorgiou G.C., Govindjee (ed.): Chlorophyll $a$ Fluorescence: A Signature of Photosynthesis. Advances in Photosynthesis and Respiration. Pp. 279-319. Springer, Dordrecht 2004.

Schreiber U., Klughammer C.: Saturation Pulse method for assessment of energy conversion in PS I. - PAM Application Notes 1: 11-14, 2007.

Schreiber U., Klughammer C.: Evidence for variable chlorophyll fluorescence of photosystem I in vivo. - Photosynth. Res., 2021. (In press)

Schreiber U., Klughammer C., Kolbowski J.: Assessment of wavelength-dependent parameters of photosynthetic electron transport with a new type of multi-color PAM chlorophyll fluorometer. - Photosynth. Res. 113: 127-144, 2012.

Schreiber U., Neubauer C.: The polyphasic rise of chlorophyll fluorescence upon onset of strong continuous illumination: II. Partial control by the photosystem II donor side and possible ways of interpretation. - Z. Naturforsch. C 42c: 1255-1264, 1987.
Sharkey T.D.: Emerging research in plant photosynthesis. Emerg. Top. Life Sci. 4: 137-150, 2020.

Shevela D., Björn L.O., Govindjee G.: Photosynthesis - Solar Energy for Life. Pp. 188. World Scientific, Singapore 2019.

Sowinska M., Cunin B., Deruyver A. et al:: Near-field measurements of vegetation by laser-induced fluorescence imaging. - Proc. SPIE 3868: 120-131, 1999.

Stirbet A.: Excitonic connectivity between photosystem II units: what is it, and how to measure it? - Photosynth. Res. 116: 189-214, 2013.

Stirbet A., Govindjee G.: On the relation between the Kautsky effect (chlorophyll $a$ fluorescence induction) and photosystem II: Basics and applications of the OJIP fluorescence transient. J. Photoch. Photobio. B 104: 236-257, 2011.

Stirbet A., Govindjee G.: Chlorophyll $a$ fluorescence induction: a personal perspective of the thermal phase, the J-I-P rise. Photosynth. Res. 113: 15-61, 2012.

Stirbet A., Govindjee G.: The slow phase of chlorophyll a fluorescence induction in silico: Origin of the S-M fluorescence rise. - Photosynth. Res. 130: 193-213, 2016.

Stirbet A., Lazár D., Guo Y., Govindjee G.: Photosynthesis: basics, history and modelling. - Ann. Bot.-London 126: 511 537,2020

Stirbet A., Lazár D., Kromdijk J., Govindjee G.: Chlorophyll a fluorescence induction: Can just a one-second measurement be used to quantify abiotic stress responses? - Photosynthetica 56: 86-104, 2018.

Stirbet A., Lazár D., Papageorgiou G.C., Govindjee G.: Chlorophyll a fluorescence in cyanobacteria: relation to photosynthesis. - In: Mishra A.K., Tiwari D.N., Rai A.N. (ed.): Cyanobacteria - From Basic Science to Applications. Pp. 79-130, Academic Press, London 2019.

Strasser R.J., Govindjee G.: The Fo and the O-J-I-P fluorescence rise in higher plants and algae. - In: Argyroudi-Akoyunoglou J.H. (ed.): Regulation of Chloroplast Biogenesis. Pp. 423-426. Springer, Boston 1992.

Strasser R.J., Srivastava A., Govindjee G.: Polyphasic chlorophyll $a$ fluorescence transient in plants and cyanobacteria. Photochem. Photobiol. 61: 32-42, 1995.

Strasser R.J., Tsimilli-Michael M., Srivastava A.: Analysis of the chlorophyll $a$ fluorescence transient. - In: Papageorgiou G.C., Govindjee (ed.): Chlorophyll $a$ Fluorescence: A Signature of Photosynthesis. Advances in Photosynthesis and Respiration. Pp. 321-362. Springer, Dordrecht 2004.

Sun D., Xu H., Weng H. et al.: Optimal temporal-spatial fluorescence techniques for phenotyping nitrogen status in oilseed rape. - J. Exp. Bot. 71: 6429-6443, 2020.

Terashima I., Inoue Y.: Vertical gradient in photosynthetic properties of spinach chloroplasts dependent on intra-leaf light environment. - Plant Cell Physiol. 26: 781-785, 1985.

Trissl H.-W., Gao Y., Wulf K.: Theoretical fluorescence induction curves derived from coupled differential equations describing the primary photochemistry of photosystem 11 by an excitonradical pair equilibrium. - Biophys. J. 64: 974-988, 1993.

Tsimilli-Michael M.: Revisiting JIP-test: An educative review on concepts, assumptions, approximations, definitions and terminology. - Photosynthetica 58: 275-292, 2020.

Vogelmann T.C., Han T.: Measurement of gradients of absorbed light in spinach leaves from chlorophyll fluorescence profiles. Plant Cell Environ. 23: 1303-1311, 2000.

Wientjes E., van Amerongen H., Croce R.: Quantum yield of charge separation in photosystem II: Functional effect of changes in the antenna size upon light acclimation. - J. Phys. Chem. B 117: 11200-11208, 2013.

(C) The authors. This is an open access article distributed under the terms of the Creative Commons BY-NC-ND Licence. 